Columbia International Publishing

American Journal of Oral Medicine

(2015) Vol. 1 No. 1 pp. 5-7

doi:10.7726/ajom.2015.1002

Image in Oral Medicine

\title{
Grooved Tongue and Congenital Muscular Torticollis
}

\author{
Antonio Celentano ${ }^{1,2^{*}}$ and Michele Davide Mignogna ${ }^{1}$
}

Received: 06 April 2015; Returned for revision: 26 April 2015; Received in revised form: 06 May 2015;

Accepted: 06 May 2015; Published online 26 May 2015

(C) The author(s) 2015. Published with open access at www.uscip.us

A 5-year-old male presented with an asymptomatic grooved and atrophic right side of the tongue (Fig. 1A), noticed 8 months before by his pediatrician as "right mild lingual deviation".

At the time of birth, the child was in good health except for right-sided congenital muscular torticollis (CMT) without plagiocephaly and clinically evident facial asymmetry. Neurologic, radiologic (including cervical-spine 3D-CT-Scan), cardiologic, hematologic, ophthalmologic, and otorhinolaryngologic tests were negative, and the patient received only 8 months of physiotherapy started at the age of 18 months.

With the suspicion of an ipsilateral CMT sequela a differential diagnostic algorithm was started excluding a hypoglossus central dysfunction through Magnetic Resonance Imaging. Ultrasonography of the head and neck region showed the presence of a $5 \mathrm{~mm}$ median cyst in submental area (Fig. 1B) and asymmetry between the genioglossus muscles (right=2.8 mm; left=5.8 $\mathrm{mm}$ ) (Fig. 1C).

Current treatment options for CMT encompass physiotherapy, surgery or other treatments like botulinum toxin. Conservative therapy includes stretching of the shortened SCM and is considered the first line of treatment. Early diagnosis and treatment are mandatory to prevent sequelae affecting the cervical range of motion and secondary musculoskeletal deformities (Jung et al., 2015; Lee et al., 2015; Nilesh and Mukherji, 2013).

In our patient we assumed that compressions of the neck anatomical structures due to CMT and to the right-sided head position could have impaired the normal growth of the genioglossus muscle acting directly or indirectly on mechanoreceptors or on the hypoglossus pre-lingual portion.

In addition, the initiation of physiotherapy was delayed, and the monitoring of the suprahyoid region muscles was insufficient.

*Corresponding e-mail: antony.celentano@gmail.com; antonio.celentano@unina.it

1 Department of Neurosciences, Reproductive and Odontostomatological Sciences, University of Naples Federico II, Naples, Italy

2 Melbourne Dental School \& Oral Health CRC, Faculty of Medicine, Dentistry and Health Sciences, The University of Melbourne, Melbourne, VIC, Australia 
Antonio Celentano and Michele Davide Mignogna / American Journal of Oral Medicine

(2015) Vol. 1 No. 1 pp. 5-7

Therefore, it is likely that the soft-tissue compression has led to abnormalities of soft-tissue differentiation causing edema, degeneration of muscle fibers and fibrosis within the involved muscles (Nilesh and Mukherji 2013). Oral Medicine specialists should regularly monitor the appearance of any supra/infra-hyoid region asymmetry through Ultrasonography.

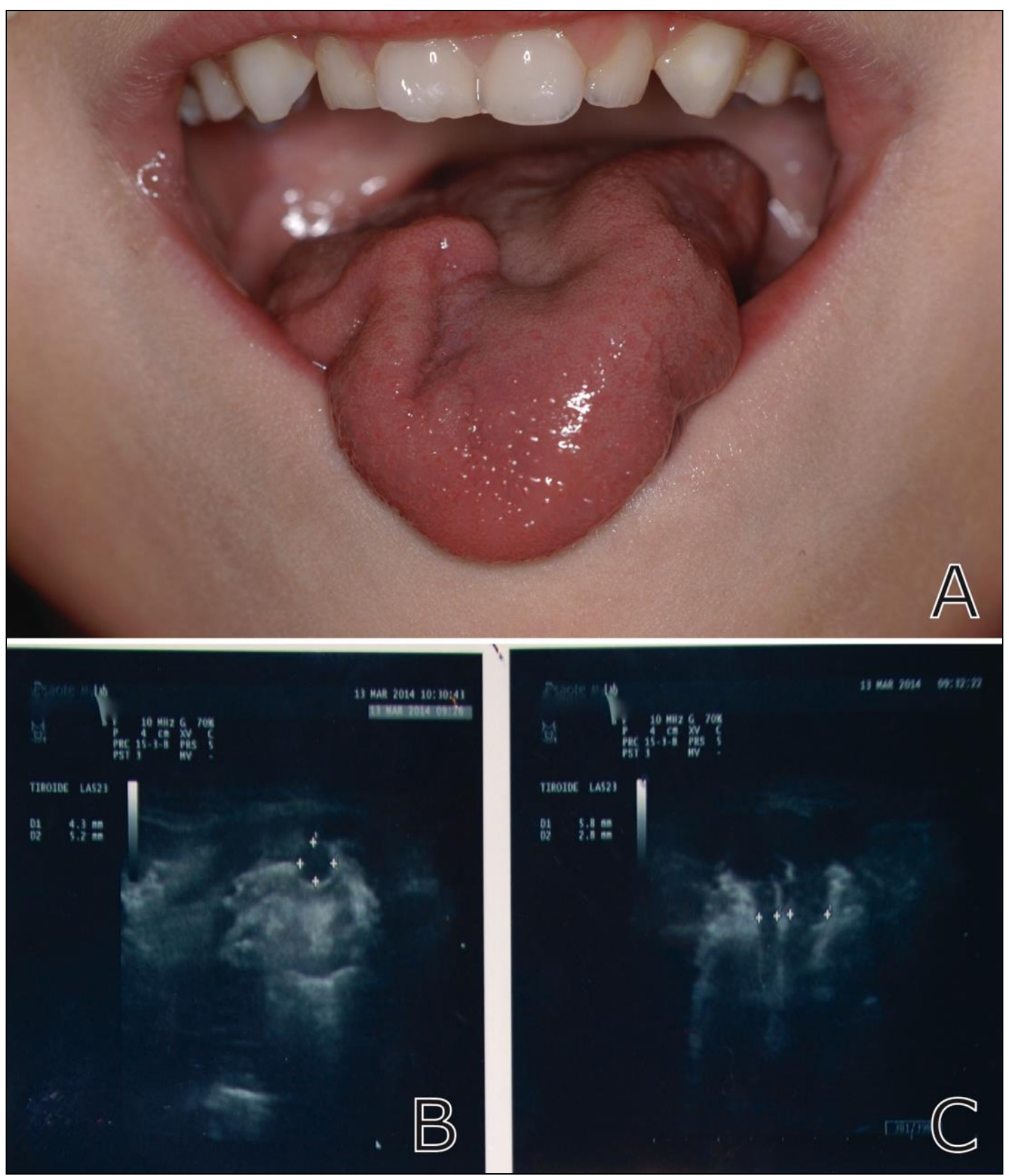

Fig. 1. 


\section{Conflict of Interest}

None

Funding

None

\section{References}

Jung, A.Y., Kang, E.Y., Lee, S.H., Nam, D.H., Cheon, J.H., Kim, H.J. (2015). Factors that affect the rehabilitation duration in patients with congenital muscular torticollis. Ann Rehabil Med, 39(1):18-24. http://dx.doi.org/10.5535/arm.2015.39.1.18

Lee, K., Chung, E., Koh, S., Lee, B.H. (2015). Outcomes of asymmetry in infants with congenital muscular torticollis. J Phys Ther Sci, 27(2):461-4. http://dx.doi.org/10.1589/jpts.27.461

Nilesh, K., Mukherji, S. (2013). Congenital muscular torticollis. Ann Maxillofac Surg, 3(2):198-200. http://dx.doi.org/10.4103/2231-0746.119222 